\title{
An Investigation of Iranian EFL learners' Use of Politeness Strategies and Power Relations in Disagreement across Different Proficiency Levels
}

\author{
Biook Behnam \\ Department of EFL, Faculty of Literature and Foreign Languages \\ Tabriz Branch, Islamic Azad University, Tabriz, Iran \\ E-mail: Behnam_Biook@yahoo.com \\ Masoumeh Niroomand (Corresponding author) \\ Department of ELT, Faculty of Literature and Foreign Languages \\ Tabriz Branch, Islamic Azad University, Tabriz, Iran \\ E-mail: commuter_60@yahoo.com
}

Received: July 8, 2011

doi:10.5539/elt.v4n4p204
Accepted: July 25, 2011

Published: December 1, 2011

URL: http://dx.doi.org/10.5539/elt.v4n4p204

\begin{abstract}
The speech act of disagreement has been one of the speech acts that receives the least attention in the field of pragmatics. This study investigates the ways power relations influence politeness strategies in disagreement. In order to determine whether and to what extent the realization of the speech act of disagreeing and the of appropriate politeness strategies by Iranian EFL learners, in a university setting, across different proficiency levels (intermediate and upper-intermediate) differ in relation to people with different power status a Discourse Completion Test (DCT) was completed by 40 Iranian EFL learners who were placed at two different levels based on their scores on a proficiency test. The DTC consists of five scenarios in which the subjects are expected to disagree with two higher statuses, two with peers and one with a lower status. The selection of disagreement situations in DCT, borrowed from studies by Takahashi and Beebe (1993) and Liang Guodong and Han Jing (2005), were based on relative power and status of people. The taxonomy from Muntigl and Turnbull (1995) was employed for counting and analyzing the utterances of disagreement from the responses. The findings of this study provide some evidences for the relation between the learners' level of language proficiency and type and frequency of disagreement and choice of politeness strategies associated with people with different power status. In conclusion, it was argued that the results can be closely related to learning contexts and textbook contents. Finally some suggestions such as making learners aware of second language pragmatic rules and socio-cultural constraints on speech acts as well as grammatical rules in order to have a successful communication were put forward regarding the issue.
\end{abstract}

Keywords: Pragmatic, Politeness, Speech act, Disagreement, Power

\section{Introduction}

In recent years, "communicative competence" has received special attention in the field of second/foreign language teaching and learning. Hymes (1972) asserts that to achieve communicative goals, second language learners must learn to speak not only accurately, but also appropriately. To communicate with each other people use language in various ways. Different functions of speech may be used to express the same meaning. Social factors such as solidarity, gender, age, or power can be regarded as the factors which influence these differences. Liu (2004, p.2) claims that "Language use is affected and constrained by socio-cultural factors, on the one hand; and individual discourse styles and communicative strategies play a role in maintaining or struggling for power, on the other hand". Therefore, in order to acquire politeness in interaction one should have a thorough understanding of these social factors. In communication, speech acts such as making requests, giving thanks, making apology, and so on can be conveyed by the use of words (Nguyen, 2009). Expressing disagreement is also seen as a speech act in which a person shows his or her dissatisfaction toward his or her interlocutor. Expressing disagreement, which is unavoidable in everyday interaction, may threaten the relationship between the interlocutors and this threat to the face of interlocutor can be softened by the use of politeness strategies (Locher, 2004). So the present study tries to 
answer following questions:

1. What is the relationship between power and politeness strategies of disagreement in Iranian EFL context?

2. What disagreement strategies do Iranian EFL learners in two groups (intermediate and upper-intermediate learners) mostly employ?

3. How do intermediate learners differ from upper- intermediate learners in expressing disagreement?

4. What types of politeness strategies are employed by these two groups to soften the impact of this inherently face threatening act?

\section{Review of Related Literature}

Acquiring pragmatic competence is a crucial factor to second language learners. According to Tanck (2002), speakers who are considered "fluent", because of their grammatical knowledge, in a foreign language, may not be able to produce socially and culturally appropriate language, that is, they may still lack pragmatic competence. Acquisition and learning of politeness strategies as a part of learning L2 pragmatics have attracted a lot of attention in second and foreign language acquisition. Studies from Brown and Levinson $(1978,1987)$ and Scollon and Scollon (1995) have attracted much attention in the study of politeness. In English politeness is characterized as "someone who is polite, has good manners and behaves in a way that is socially correct and not rude to other people" (Co build English Dictionary for Advanced Learners, 2001).

The general assumption of Brown and Levinson' (1978) theory of politeness is that many speech acts like, requesting, criticizing, and disagreeing are intrinsically threatening to face. Speech acts are threatening because they do not consider the face wants of the interlocutors. Brown and Levinson (pp. 65-67) defined face-threatening acts (FTAs) according to two basic variables: (1) Whose face is being threatened (the speaker's or the addressee's), and (2) Which type of face is being threatened (positive- or negative- face). Acts that threaten an addressee's positive face include those acts in which a speaker demonstrates that he/she does not support the addressee's positive face or self image (e.g., complaints, criticisms, accusations, interruptions). Acts that threaten an addressee's negative face include instances in which the addressee is pressured to accept or to reject a future act of the speaker (e.g., offers, promises). By applying Brown \& Levinson's (1987) theory to the speech act of disagreement, it becomes clear that this speech act is most likely to constitute a threat to the hearer's positive face as " a speaker is imposing her/his will on the hearer "(p. 65).

In comparison to the other speech acts (requesting, complaints, criticisms), the study of disagreement especially in Iranian context has attracted less attention in the study of speech acts. Brown and Levinson (1987) propose that when confronted with the need to perform a FTA, the individual must choose between performing the FTA in the most direct and efficient manner, on record or attempting to mitigate the effect of the FTA on the hearer's face, doing it off record. The strategy an individual chooses to employ depends upon the weightiness or seriousness of FTA. Weightiness is an assessment of the social situation calculated by the speaker (p. 76). The speaker considers three variables when assessing weightiness: the degree of imposition, the relative power of the hearer, and the social distance between the speaker and the hearer. When performing specific acts, politeness strategies try to redress in some way the threat to positive and negative public self-image. Positive politeness aims at supporting or enhancing the addressee's positive face, whereas negative politeness aims at softening the aggression on the addressee's freedom of action or freedom from imposition. Brown and Levinson (1987, p.77) assert that "[p]ower is an asymmetrical social dimension of relative power". Despite the difference of power between interlocutors, they suggest that speakers with higher-status may use more politeness strategies in their speech compared with lower-status participants. The concept of power is believed to closely correlate with negative politeness, of not wanting to impose on others, allowing others to have the freedom to act. For Liu (2005) power means "status" in which professors, administrators, and students are on a hierarchy from powerful to powerless. The speaker is required to have pragmatic competence of language use in a language as well as linguistic competence to perform the speech act appropriately. The speech act of disagreement is a face-threatening act when the speaker ignores the cultural and social values of the speaking and this can cause a communication breakdown. In fact, due to the lack of enough pragmatic competence, it is frequently observed that nonnative speakers fail in successful communication in a target language. Scollon and Scollon (1993) also assure that violation of pragmatic rules lead to communication breakdowns. Appropriateness of language use can be realized by acknowledging the social identity of the listener in terms of the relative social status, power relations and the level of familiarity between participants (Moon, 2001).

Kreutel (2007) in his article "I'm not agree with you." analyzed the devices used by learners of English as a Second Language in order to perform the speech act of disagreement in their L2. This study revealed that, NNSs employ desirable features less frequently than NSs and display a higher frequency of undesirable features. It was found that 
non-native speakers use mitigational devices such as hedges or explanations less frequently than native speakers, but often resort to undesirable features such as the "blunt opposite" or message abandonment.

Honda (2002) investigated the structure of conflict talk on a face-to-face interaction through investigating how disputes and confrontations are expressed and managed in episodes from three Japanese public affairs talk shows. The findings revealed five kinds of management: untargeted opposition, mitigation markers and modifiers, agreement or cooperative acts, intervention by another participant, and intervention by the moderator. He demonstrates that the mitigating action, 'facework', has occurred systematically in every conflict episode throughout the show.

Dogacay-Aktuna and Kamisli (1996) investigated discourse strategies status unequal interlocutors use in expressing disagreement. It also compared and contrasted the discourse strategies by native speakers of Turkish and American English in the same speech event to obtain a cross-cultural perspective. It revealed semantic formulas as affected by the relative power and status of interlocutors. The comparison of Turkish and American disagreement revealed that status difference which proved not to be an important factor on Turkish work place interaction, was a very important factor in American setting. American and Turks both in the higher and lower status applied the same type of formulas, but with totally different frequencies. In comparison to the Turks, American was much more careful in redressing their disagreement with initial positive statements and politeness markers. Status difference was not very apparent with respect to the frequency of politeness formulas that are employed by the Turkish subjects.

Rees-Miller (2000) investigated the act of disagreement in terms of the factors of power, severity and context in university courses and academic talks in the United States of America. The study revealed that professors use more positive politeness strategies when disagreeing with students than do peers disagreeing with each other or students disagreeing with professors.

Beebe and Takahashi (1989) in "Do you have a bag" looked at American and Japanese performance on two face threatening acts, namely disagreement and giving embarrassing information. The results revealed that American were not always more direct and explicit than Japanese. Also cross-cultural studies by Beebe and Takahashi (1989), Takahashi and Beebe (1993) on Japanese and Americans on various speech acts revealed that in comparison to the Japanese who are not so indirect, Americans, especially when interacting with a higher status people, use more positive remarks and they are more polite and more indirect. In contrast, when Japanese disagree with a higher status interlocutor, they were more direct and explicit. Both groups used different strategies in English according to the status of the interlocutor.

Nguyen (2009), in her paper, "Politeness Strategies in Showing Disagreement in Group Work" compared and contrasted Vietnamese and American undergraduate students' performance. Since the participants in her study were all undergraduate students, the relationship between respondents was the same. It is found that both of the two groups of respondents prefer using non- conflicting disagreement strategies than conflicting ones and they mostly express their disagreement in a non-threatening way with the assumption that if they show their disagreement aggressively, the group's relationship will be broken. The data revealed that, the male respondents of both groups tend to be more direct than the female respondents. By comparing the result of two groups it was found that, the American male and female respondents use more "non- confrontational" strategies than the Vietnamese male and female respondents. This means the American respondents tend to be more indirect and less aggressive than the Vietnamese respondents. They are more careful to save the face of their interlocutor and do their face threatening act off record.

The study by Guodong and Jing (2005) is a contrastive study on disagreement strategies for politeness between American English and Mandarin Chinese. Five scenarios for disagreement were devised for college students in USA and Chinese mainland to fill in what they would say when they disagree with the higher-status, peers and the lower-status. The findings revealed that, when disagreeing with the superior, Chinese students employ more politeness strategies and address forms than the American students do. In the case of peers, with the increase of social distance, both the American and Chinese students apply less and less politeness strategies. Positive correlation was found between the rates of disagreement and the change of the social distance for the Chinese students while negative correlation for the American students. When disagreeing with the sister, the Chinese male uses the least politeness strategies while the Chinese female uses the most politeness strategies. Female students behave more sensitive to politeness and use more politeness strategies than male subjects do.

Although empirical studies have provided insights into these concepts in numerous cultures, up to the present day, a limited number of studies in Iranian, Persian/Turkish/ context have considered these areas. 


\section{Methodology}

\subsection{Introduction}

It is generally believed that power relations influence politeness strategies in performing different speech acts. To investigate Iranian EFL learners' use of Politeness Strategies and Power Relations when expressing the speech act of Disagreement, a Discourse Completion Test was given to the subjects in two different groups. They were requested to write their natural responses to five situations representing the designated speech act. The "Discourse Completion Test" borrowed from studies by Takahashi and Beebe (1993) and Guodong and Jing (2005).

\subsection{Participants}

The current research project was conducted in Tabriz, Iran. This community was selected for the current investigation because no previous study on disagreement and politeness had been conducted there. Altogether 40 English major college students, who were born in Iran and have never stayed in English-speaking countries, including 35 females and 5 males, filled in the English version of the Discourse Completion Test (DCT). The participants' age ranged from 19 to 25 and they were from different regions of Iran. All these participants also were given Language Proficiency Test (PET 2004). They were then divided into two groups representing 20 intermediate and 20 upper-intermediate EFL language learners.

\subsection{Design}

The approach used in this study was survey based. In order to investigate the relationship between power and politeness in the realization of disagreements, the participants in two groups were given DCT which consisted of five scenarios. The questionnaire used here presented a brief description of certain situations, which specified the setting, the social distance between the interlocutors and their status relative to each other. When identifying the utterances of disagreement from the responses, the taxonomy from Muntigl and Turnbull (1998) were applied. Then responses of students were compared with Brown and Levinson's politeness strategies.

\subsection{Instruments}

To collect data for this study, two main instruments were used: English language proficiency test, PET (Preliminary English Tests, 2004)," Demographic Survey" and a "Discourse Completion Test", (DCT) (appendix 1). In the "Demographic Survey", the subjects were requested to give basic information such as age, gender, level of education and first language. The learners were further asked to give information about their English learning environments, length of period of English study, frequency and context of English use. The DCT is a form of questionnaire describing some natural situations to which the respondents are expected to react, making disagreement. In this case the (DCT) consists of five scenarios, in which the subjects are expected to disagree with two higher statuses, two peers and one with a lower status and then, they will be asked to write their natural responses for each situation.

\subsection{Data collection procedure}

Prior to the actual data collection, the situations in the original studies were radically modified and adapted to suit the Iranian context. The modified form of the (DCT) is given to two professors for validation. Their suggestions and observations are well taken into consideration in designing the final form of the (DCT). For further validation, the (DCT) was piloted on six subjects, similar to the main group, not included in the sample to see if the language was comprehensible for EFL learners, and based on their opinion a few changes were made. After this stage, to assign students into two proficiency levels, in one session an English language proficiency test (PET, 2004) including questions in reading and writing was given to the participants. The participants, whose score were between 50 and 65 , were considered as intermediate, those whose score were above 65 were considered as upper-intermediate and the students whose score were below 50 were sacked from the study. After a week interval, a DCT was administrated to the selected students in two different groups in their classes at Islamic Azad University, Tabriz branch. The data was collected by means of this questionnaire that was administered to about sixty EFL students. The important point that needs to be mentioned here is that while sixty students were asked to do the questionnaire, about fifty questionnaires were returned, and out of fifty, forty of them were analyzed as they included incomplete/ misunderstood responses. Selection of disagreement situations in DCT was based on social factor of relative power. The DCT consists of five scenarios, in which the subjects were expected to disagree with a higher status, three with peers and one with a lower status. The scenarios covered a variety of topics and types of situations to avoid intervening effects of topic selection. The participants were asked to produce appropriate disagreement utterances for a given context of situation in DCT. These contexts were selected as they will think to occur frequently. The students in both groups were given enough time to write their answer to each situation. As English was not the participants' native language, the wording of the questionnaire was kept rather simple to minimize any misunderstanding. In the case of intermediate learners, it was decided that the researcher would be available during 
the questionnaire administration to provide assistance.

\subsection{Data analysis}

The participants' responses were analyzed in three steps. First, invalid responses were discarded and the total number of valid responses was determined. In the second step, when identifying the utterances of disagreement from the responses, the taxonomy from Muntigl and Turnbull (1998), which recognizes five types of disagreement: irrelevancy claim, challenge, contradiction and counterclaim and contradiction followed by counterclaim was applied.

Fig 1: Muntigl and Turnbull (1995, p: 60)

In this step, the actual disagreement realizations were analyzed. First, the occurrences of the features in question were counted for intermediate and upper-intermediate learners and subsequently they were compared. Second, possible relationships between proficiency level and disagreement realizations were analyzed.

Muntigl and Turnbull (1995, pp.39-45) identify four types: Irrelevancy Claims (IC), Challenges (CH), Contradictions (CT) and Counterclaims (CC). They define them as follows. Irrelevancy claims are "meta-dispute-acts that comment on the conversational interactions". They show that a previous claim is not relevant to the discussion of the topic at hand. These are marked by words and expressions like It doesn't matter; You're straying off the topic; and It is nothing to do with it. In uttering them, speakers seem to be questioning or undermining their interlocutors' previous claims by stating that their claims are not relevant to the discussion at hand.

Challenges have typically the syntactic form of interrogative with question particles such as when, what, who, why, where and how. These are statements in which an interlocutor disagrees with prior turn. This type does not make a specific claim (e.g. why or like who); it implicates that the addressee cannot provide evidence for his claim. Challenges imply that the addressee cannot provide evidence for his/her claim. By posing a threat to the positive face of the interlocutor, challenges might be considered as impolite.

In Contradictions, "a speaker contradicts by uttering the negated proposition expressed by the previous claim" (p. 42). These are often marked by negative particles like no or not as in (No, I don't), indicating that the contradiction of the prior claim is true. As Brown and Levinson $(1987$, p.66) assert in their seminal paper, these acts make the hearer appear to be "wrong or misguided or unreasonable about some issue, such wrongness being associated with disapproval." Sometimes instead of having negative contradiction markers, contradictions will have "positive contradiction markers" like, yes or yeah which in contrast to the negated claim, state positive statements.

With counterclaims, speakers propose an alternative claim that does not directly contradict or challenge others' claim. Further negotiation of the previous claim is provided by them. They tend to be preceded by pauses, prefaces, and mitigating devices (e.g. maybe your right, but). The strategies of avoiding explicit disagreement such as using positive markers, partial agreement or hedges can indicate indirectness and being polite in the speech act of disagreement.

Muntigl and Turnbull (1998) propose that there exist a fifth type in which disagreement type is the combination of contradictions followed by counterclaims.

In the next step, the taxonomy of politeness strategies for disagreement developed by Brown and levinson was employed for counting and analyzing the politeness strategies.

Figure 2: Five politeness strategies (Brown \&Levinson 1987, p.69)

\section{Results and Discussion}

In this part the findings of the study will be presented and discussed. Responses of both intermediate and upper-intermediate subjects will be compared and discussed separately for each situation. Using Brown \& Levinson's (1987) definitions and assumptions about disagreement, it was found that speech act of disagreement is most likely to constitute a threat to the addressees positive face as disagreement usually questions the recipient's competence or even truthfulness and thus damages his or her self-image. The questionnaire describes situations that students in an Iranian college, university setting or everyday life may encounter, and seeks to elicit responses to such situations. The data including responses to the five disagreement situations given in the questionnaire (DCT) consist of five scenarios, in which the subjects are expected to disagree with two higher statuses, two with peers and one with a lower status. All of these situations were grouped according to power and distance among interlocutors; for instance, situation 1 and 2 involved a professor and a boss, who represent varying degrees of distance and power to the hearers. Situations 3 and 4 included interaction between peers and last situation with a sister who is in lower position than the speaker. The last three situations included relatively informal situations. Although a large number 
of responses were gathered, for various reasons, several responses had to be discarded.

\subsection{Types of disagreement}

In order to identify the type and frequency of disagreement strategies made by Iranian EFL learners across two different proficiency levels, using taxonomy from Muntigl and Turnbull (1995), which recognizes five types of disagreement: irrelevancy claim (IC), challenge $(\mathrm{CH})$, contradiction $(\mathrm{CH})$, counterclaim $(\mathrm{CC})$ and contradiction followed by counterclaim, the data were analyzed. In this taxonomy they rank the disagreement types from the most to the least face "aggravating". Irrelevancy claim (IC) is the most face-threatening disagreement in which a speaker questions the relevancy of previous claim to the discussion at hand. The second disagreement type in this taxonomy is challenge $(\mathrm{CH})$ in which the speaker demands that addressee provide supporting evidence for his and her claim. Contradiction (C) is the next type of disagreement in which a speaker explicitly contradicts with the previous claim, but it is less face-threatening than IC and $\mathrm{CH}$ in that it does not decline the capability of other interlocutor. Another type of disagreement is counterclaim that is the least face-threatening act. In this case the speaker does not contradict directly. By bringing reason for disagreement and using positive markers, $\mathrm{CC}$ mitigates threat and damage to the others' positive face (Peter Muntigl 1995).

This analysis involved both qualitative and quantitative, independent examination of each response for the five situations. Frequency of occurrence of these components as used by intermediate and upper intermediate learners is presented in tables for each situation.

\section{Situation: 1}

Your supervisor questions the originality of the term paper you submit. S/he says to you,

"I'm sorry, but I don't think these ideas are yours." However, they are yours. In response, you will say,

$"$ ".."

In response to this situation, in which the speaker is disagreeing to his or her supervisor who questions the originality of the term paper she or he submits, both intermediate and upper-intermediate learners applied almost the same types of disagreement, but with different levels of frequency. The frequency by which both groups used different types of disagreement for this situation is summarized in Table1 and Figure 1.

In this situation, which contains certain kind of formality, a power inconsistency exists between interlocutors. The person, who the speaker is disagreeing with, is in a higher power and position than the speaker. As illustrated in table $1,45 \%$ of upper-intermediate subjects performed disagreement using counterclaims and $20 \%$ of this group performed disagreement using contradictions followed by counterclaims (e.g. Teacher, I don't know how I can prove it, but believe me they are definitely my own ideas). These are implicit without directly disagreeing to the person. Interestingly, only $20 \%$ of intermediate learners performed disagreement in the same way. These kinds of disagreements are violation of the maxims of manner and quantity (Say no more than the conversation requires, don't be obscure, don't be ambiguous, be brief, and be orderly).

The next favored disagreement type in this situation was contradictions with the frequency of $35 \%$ for intermediate learners and just $15 \%$ for the upper-intermediate learners (no, you misunderstood, if I wrote them I know they are mine). Only a limited number of learners, $20 \%$ of intermediate learners and $10 \%$ of upper-intermediate learners, used challenges to express their disagreement (why do you think that I tell a lie!). IC was the least favored way of disagreeing by two groups ( $15 \%$ of intermediate learners and only $5 \%$ of upper-intermediate learners). Because of their face threatening nature, Irrelevancy claims are considered as impolite way of disagreeing. Only three out of forty subjects didn't answer this situation.

Situation 2

You work in a company. Your boss presents you with a plan for reorganization of the department that you are certain will not work. Your boss says isn't it a great plan? In response, you will say, $"$ ."

In this context, in that an employee disagrees with his or her boss, a power asymmetry exists between the interlocutors. Similar to the first situation both groups used the same types of strategies to show their disagreement, but again with different level of frequencies. Types and frequencies with which two groups performed the speech act of disagreement are presented in Table2 and Figure 2.

Because of power differences between interlocutors and attention to the face needs of the interlocutor, counterclaims, $55 \%$ by upper-intermediate subjects and $30 \%$ by intermediate subjects (e.g. it's a good plan, but I think we can try another plans), and contradictions followed by counterclaims, $25 \%$ by upper-intermediate subjects and $15 \%$ by 
intermediate subjects, were the most favored strategies which were used by both groups in this situation (e.g. sir you may be right, but my opinion is a little different from yours). Irrelevancy claims and challenges were used only by a few numbers of intermediate participants (10\% irrelevancy claims and challenges $15 \%)$. Only one of the upper-intermediate subjects performed act of disagreement by challenges (why you don't try another plan, I'm sure it won't work). Four out of twenty intermediate subjects didn't answer this situation.

\section{Situation 3}

Your friend makes the following comment on your thesis, "I think you should supply more data to support your arguments. You know, your conclusion is a little bit weak."

However, you think that there has been enough evidence and the problem is how to give a better explanation of the data. In response, you will say,

In situation three in which the interlocutors are status equal, we may find far fewer contradictory statements, which indicates that friends are concerned about the friends' face wants. Still, higher frequencies of intermediate learners than upper-intermediate learners are found to use contradictory statements in expressing their disagreements. The frequency of use (by both groups) of disagreement strategies for this situation is summarized in Table 3 and Figure 3.

The above data revealed that the upper-intermediate learners are more careful in making disagreement to a friend who questions his or her thesis. In comparison to the intermediate subjects (25\%), a large numbers of upper-intermediate subjects $(60 \%)$ used counterclaims to express their disagreement (e.g. maybe this is resulted from time limitations; maybe later I try to expand it, but not now). Contradictions followed by counterclaims, "my conclusion is based on real evidence, but I try more", with the frequency of $20 \%$ were the next favored strategies by upper-intermediate subjects. In order to reveal their disagreement, $25 \%$ of intermediate subjects and $10 \%$ of upper-intermediate subjects used contradictions. For example their answer was, "why do you question my thesis without having any knowledge about it". In expressing their disagreement, 30\% of intermediate learners used irrelevancy claims $(15 \%)$, and challenges (15\%). Only two upper-intermediate learners applied these strategies in expressing their disagreement (5\% irrelevancy claim and 5\% challenge). One example of irrelevancy claims is: "so do think my conclusion is weak. Two out of 20 intermediate subjects (10\%) kept silent.

\section{Situation 4}

In a seminar class on the effect of modern technology, one of your classmates says, "The so-called modern technology is endangering the environment. It causes too much pollution". However, you believe such problems are only temporary and can be solved gradually. In response, you will say:

$"$

Although in this situation the interlocutors are status equal, the social distance is larger in this situation than situation three. The result revealed that with the increase in social distance, the upper-intermediate subjects used more contradictory statements than the previous situation. In response to this situation, the upper-intermediate subjects and the intermediate subjects made same forms of disagreement. The differences are in the frequency with which they use these strategies. Table 4 and Figure 4 indicate these differences.

Table 4 and Figure 4 show that the two groups used the same types of strategies, but they again differ in the percentages with which these strategies are used.

Again the percentages of contradictory statements by intermediate learners (irrelevancy claims $20 \%$, challenges $20 \%$, and contradictions 35\%) are much more than upper-intermediate learners (irrelevancy claims 5\%, challenges 15\%, and contradictions 20\%), (e.g." no you are wrong, I'll bring some good reasons"). Although some increases were seen in the use of contradictory statements by upper-intermediate subjects, again this group was more inclined to the use of less contradictory statements (counterclaims 35\% and Contradictions followed by counterclaims 20\%) than intermediate subjects(counterclaims $20 \%$ and Contradictions followed by counterclaims $5 \%$ ), ("you're right, but they me solved gradually"). The only person who didn’t answer this situation was from intermediate group.

\section{Situation 5}

You are watching the movie Titanic with your younger sister at home. When the ship is about to sink and the first mate calls out, "Women and children first" to get on the lifeboat, your sister suddenly blurts out, "It's really unfair and prejudiced to women: we're no weaker than men. Why should women instead of men go first with the children?" In your opinion, women are, physically speaking, not as strong as men. Your response will be: 
$"$ $"$

In response to this situation in which the speaker is disagreeing with his or her sister, both of the groups applied almost similar disagreement types, but with different levels of frequency. The responses of both intermediate and upper-intermediate learners are summarized in Table 5 and Figure 5.

In this situation, a speaker is disagreeing with an interlocutor of an unequal status. In this case, contrary to the first and second situations, this is the speaker who possesses higher status and power. Counterclaims $(50 \%)$ were used by the upper-intermediate subjects as twice as much as the intermediate subjects $(30 \%)$, ("women and children are weaker physically, but they are so strong mentally"). The two groups used contradictions followed by counterclaims with almost similar levels of frequency. However, when it comes to the more explicit contradictory statements more intermediate learners (irrelevancy claims $20 \%$ ("so you think it's unfair to women", "it's nothing to do with"), challenges $15 \%$, and contradictions $10 \%$ ) than upper-intermediate learners (irrelevancy claims $5 \%$, challenges $10 \%$, and contradictions $15 \%$ ) used these strategies.

\subsection{Politeness strategies}

The findings of this study provide some evidence of relationship between learners' level of language proficiency and type of disagreeing. Although both of the intermediate and upper-intermediate groups were concerned about politeness, these two groups revealed much difference in the application of contradictory statements and politeness strategies. The results of the study showed that upper-intermediate learners are more sensitive about power and status of their interlocutor and applying politeness strategies. The present study confirms the most general finding from the previous studies, namely high proficiency (upper-intermediate) learners, because of their linguistic competence, employ desirable features more frequently than low proficiency (intermediate) learners. In line with agreement maxim (Leech, 1983), this finding means that the upper-intermediate learners attempt to minimize the disagreement between themselves and others much more than intermediate learners. It was also found that the intermediate subjects are more aggressive in expressing disagreement than intermediate group.

Due to the certain kind of formality which exists between the interlocutors, the contexts 1 and 2 can be looked at as almost the same. In both of these contexts, the speaker should disagree with a person who is in a higher position than the speaker himself. In response to the first and second scenarios, counterclaims occurred most frequently. These are implicit without directly disagreeing to the person. Because a power inconsistency exists between interlocutors and the person who the speaker is disagreeing with, is in a higher power and position than the speaker, majority of the subjects in the upper-intermediate group preferred performing the FTA off record, i.e., indirectly by the use of partial agreement and positive remarks to mitigate their disagreement. Off-Record Indirect politeness strategy outlined by Brown and Levinson (1987) uses indirect language and removes the speaker from the potential to be imposing. These are the tendency to agree and save the hearer's positive face by "claim[ing] common ground" (Brown \& Levinson, 1987, p. 103). By Brown and Levinson's term, disagreement, inherently threaten either the hearer's or the speaker's face-wants, and that politeness is involved in redressing those face threatening acts. This is in line with the findings of Pearson (1986) and Beebe and Takahashi (1989) that native speaker's strategies for expression of disagreement are generally characterized by mitigation, that is, by means to reduce the directness of the disagreement and with it the strength of the FTA. Contrary to the upper-intermediate group, without recognizing the requirements of this situation and face wants of their interlocutor, explicit and direct contradictory statements, bald on record, were the most apparent way of disagreeing among intermediate group. Bald on-record strategies usually do not attempt to minimize the threat to the addressee's face, although there are ways that bald on-record politeness can be used in trying to minimize FTA's implicitly. Doing an act baldly, without redress, involves doing it in the most direct, clear, unambiguous and concise way possible. Such high rates of explicit disagreements may seem contradictory to the arguments of Brown and Levinson, and Scollon and Scollon on the effect of power on politeness, but it is in accordance with maxim of manner. Disagreement threatens the hearer's positive face; therefore it would be expected positive politeness strategies (Brown \& Levinson, 1987). In these two situations only a few numbers of intermediate group applied positive politeness strategies, such as partial agreement and positive remarks, to save the face of their interlocutors. Positive face is threatened when the speaker or addressee does not care about their interlocutor's feelings, wants, or does not want what the other wants.

In line with findings of Kreutel (2007), intermediate subject's expressions of disagreement included linguistically simple and short statements. They were mostly characterized by the absence of the surface features established for native-like language use, which in turn results in an overall lack of mitigation. As a result, intermediate learners appeared unpleasant, too direct, or even rude. Bell (1998), observed with Koreans apart from the lake of redressive devices, ESL learners' expressions of disagreement include explicit no as well as the direct statement of the opposite.

Address terms (e.g. teacher, boss, sir and professor) as an indicator of politeness were used by both groups. 
According to Wolfson (1989:79) address terms are a "very salient indicator of status relationship". The analysis revealed that lower status interlocutors in the first and second scenarios used address terms more frequently. This result is similar to the findings of Dogancay-Aktuna and Kamisli's (1996) study, "Discourse of power and politeness, through the act of disagreement", on native speakers of Turkish and American speakers. They found that lower status interlocutors used more address terms than higher status interlocutors. In this study address terms were more frequent in the first and second situations because just in these two situations the interlocutors were expected to disagree with higher status persons. Although both groups made use of address terms while disagreeing with higher status interlocutors, a thorough analysis indicated that when speaking to a person of higher status, the intermediate learners may use the address form much more frequently than upper-intermediate learners. This is in line with the findings of Guodong and Jing (2005) that the Chinese students use the address form in a significantly higher frequency than their American peers. In these two situations, the subjects violated the maxim of manner (Grice, 1975). Maxim of manner wants every conversationalist speak directly, not ambiguously and abundantly. According to Leech (1993:3), Grice's cooperative principle (1975) could not always answer why the participants in a talk exchange are more apt to use indirect way to convey their meaning and politeness has a very important rule in a society, and it is needed to elaborate cooperative principle and also a completion of cooperative principle. The participants in a conversation not only consider the cooperative principles as suggested by Grice (1975) but also politeness maxims. In his original paper, presenting the maxims, Grice explained maxims as systematic ways that natural language differs from logical language.

The findings revealed that in disagreeing to a friend in the third situation, the upper-intermediate group was more careful about face wants of their interlocutor than intermediate group. In friendly conversations, which account for a large amount of conversational encounters, speakers show reluctance and hesitance to express disagreement (Beebe \& Takahashi, 1989). They used various kinds of mitigating devices to reduce the threat to the face of their interlocutor. This finding has similarity to the finding of Umar (2006) that the Sudanese learners are more "reserved" in making complaint to a friend and they use too modest ways in complaining to their friends. In comparison to the upper-intermediate group, who preferred to act their disagreement off record, which means flouting one of the Gricean (1975) maxims (maxim of manner) on the assumption that the addressee is able to infer the intended meaning, and implicitly, the intermediate learners preferred most direct and simple on record way of disagreeing. This may result from the fact that direct disagreement is easier to utter than indirect disagreement. Direct statements have very simple structures and they are shorter. This finding is similar to the findings of Moon (2001) on complaints of NSs and NNSs. In his study it was found that the complaints of NSs tended to be longer than those of NNSs. NS subjects made complaints with a combination of the components of complaints which made their complaints longer. When interacting, the interlocutors possess the necessary pragmatic knowledge, but do not know how to realize it due to limited linguistic knowledge (Takahashi \& Beebe, 1993). According to them, among NNSs, the higher the proficiency level, the more appropriately they will make complaints and the hypothesis. This result seems to be contrary to the Brown and Levinson's (1987, pp.68-71) model of strategies for performing face-threatening acts and their discussion of factors influencing the choice of strategies (1987, pp. 71-83). They imply that more direct strategies of disagreement would be used in preference to less direct strategies when there is less social distance between speaker and addressee, when the speaker has greater power than the addressee, and when the rating of imposition on the hearer is less (1987, p. 83).

Situation 4 involves interaction between status equal interlocutors; however, the social distance is larger in this situation than situation three. The result revealed that with the increase in social distance, the upper-intermediate subjects used more contradictory statements than previous situation. This result affirms the findings of and Jing (2005) on their Contrastive Study on Disagreement Strategies for Politeness between American English and Mandarin Chinese.

They found that with the increase of social distance (from friend to classmate to stranger), American students use more contradictory statements and less politeness strategies. But again the total numbers of contradictory statements by upper-intermediate subjects were less than intermediate subjects. Majority of intermediate group uttered their disagreement bald on record without redressing it by the use of politeness strategies.

The result of the last situation, in which $50 \%$ of upper- intermediate subjects uttered their disagreements off- record, have similarities with Guodong and Jing (2005) studies in that they found that in the American families the older sister or brother treats the younger sister with equal power status and use more positive remarks when disagreeing with them. When they want to disagree with younger sister or brother, they bring acceptable reasons for their disagreement. Brining convincing reason for disagreement by use of softener will result in performing the communicative act of disagreement less imposing on the listener, mitigating the threat on the face of the listener, doing it off record to save positive and negative face of the interlocutor. Contrary to the upper- intermediate subjects 
and findings of Liang Guodong and Jing (2005) of American subjects, the most preferred disagreement types by the intermediate group were bold on record, direct.

It was found that, throughout the five situations, some of the subjects in the intermediate group expressed their disagreement implicitly (indirect level or off-record strategies) by the use of mitigating devices and positive markers. It shows that even the low learners are able to select a polite, conventionally indirect strategy in the L2, and they are careful about face wants of their interlocutors. Inappropriate performance of learners in different disagreement situations may be resulted from their linguistic limitations. This result is in accordance with the findings of Umar (2006) by Sudanese learners on the speech act of complaint and Jalilifar (2009) by Iranian subjects on request strategies. They found that lower proficiency learners may, to some extents, have pragmatic competence, but they lack sufficient linguistic competence to perform appropriately in a foreign language. The higher the proficiency level, the more appropriately they will utter their disagreements.

When identifying the utterances of disagreement from the responses, it was found that eleven out of forty subjects didn't provide answers to some of the situations. Only two out of twenty of subjects who didn't answer some situations were upper-intermediate learners. This again may be resulted from linguistic limitations of the subjects. Kreutel (2007) stated that" ESL learners often lack appropriate disagreement strategies, which makes their utterances appear impolite and rude, and which may even result in message abandonment". According to the Moon "Saying nothing" is an extreme form of implicit complaints". It was discovered from the collected data that the disagreeing expressions were uttered with both single and combined strategies and by the use of bald on record, positive and negative politeness strategies. Claims of irrelevancy, which are "Flouting" a maxim (violation of relevance maxim) to create a conversational implicature, were so apparent in the intermediate subjects' responses.

The results of this study indicate that with increasing proficiency level, learners use of direct, baldly on record way of disagreeing decreases and indirect, off record way of disagreeing increase. The examination of the first question revealed that the power status of people have strong effects on Iranian EFL learners, in both groups, choice of politeness strategies when disagreeing. The investigation of second question revealed that students in both groups make use of the same strategies, but with different frequencies. The results of third question showed that upper-intermediate learners of this study, because of their high linguistic proficiency, are more careful about the face wants of their inter locators and choice of appropriate politeness strategies than intermediate group. It was found that when disagreeing, the EFL learner try to make use different politeness strategies to soften their disagreements.

\section{Conclusion}

This study was designed to address the important issue of politeness strategies and power relations in disagreement across different proficiency levels as used by Iranian EFL learners in order to determine whether and to what extent choice of appropriate politeness strategies and the speech act of disagreement by Iranian learners differs in relation to people with different power status. The present study suggested a mutual relation between the uses of particular kind of politeness strategies in showing disagreement to people with different power status. It revealed that learners are more sensitive to the use of more politeness strategies in disagreeing to high status people than low status people. It was found that L2 learners may have access to the range of speech acts and they may have enough pragmatic competence, but they may use just limited number of these strategies due to the lack of linguistic competence. More importantly, even in the high proficiency levels, EFL learners fail to act out different functions of speech appropriately, so L2 learners must be aware of second language pragmatic rules and socio-cultural constraints on speech acts as well as grammatical rules in order to have a successful communication. Although EFL learners are highly context-sensitive in selecting pragmatic strategies in their own language, they may don't pay attention to such variables as social distance and social power in L2 (Rose and Kasper, 2001).

It is important to note that, as predicted by politeness theory (Brown \& Levinson, 1987), power relationship, social distance, and degree of imposition constrain communicative action universally, but the value of these factors vary from context to context. So, in order to have successful communication, it's important that each community provide enough knowledge for their people about these factors and politeness strategies.

Finally, it is hoped that research in second language politeness strategies, will enable us to incorporate effective methods of teaching politeness strategies in the EFL classrooms.

\section{References}

Al-Tayib Umar, A. M. (2006). The speech act of complaint as realized by advanced Sudanese learners of English. Umm Al-Qura University. Journal of Educational \& Social Sciences \& Humanities, 18, 2, Jumada II 1427AH.

Bargiela-Chiappini, F. (2003). Face and politeness: New (insights) for old (concepts). Journal of Pragmatics, 35, 1453-1469. http://dx.doi.org/10.1016/S0378-2166(02)00173-X 
Brown, P., \& Levinson, S. (1987). Some universals in language usage. Cambridge: Cambridge University Press. Fairclough, N. (1989). Language and Power. London: Longman.

Gruber, H. (1998). Disagreeing sequential placement and internal structure of disagreements in conflict episodes. Text, 18, 467-503

Guodong, L., \& Jing, H. (2005). A contrastive study on disagreement strategies for politeness between American English \& Mandarin Chinese. Asian EFL Journal, 7, 10(1)

Hatch, E. (1992). Discourse and language education. Cambridge Language Teaching Library: Cambridge University press.

Honda, A. (2002). Conflict management in Japanese public affairs talk shows. Journal of Pragmatics, 34, 573-608

Jalilifar, A. (2009). Request strategies: cross-sectional study of Iranian EFL learners and Australian native speakers. English Language Teaching Journal, 2(1), 790-803

Ji, S. J. (2000). 'Face' and polite verbal behaviors in Chinese culture. Journal of Pragmatics, 32, 1059-1062. http://dx.doi.org/10.1016/S0378-2166(99)00068-5

Kakava, Ch. (2002). Opposition in Modern Greek discourse: Cultural and Contextual constraints. Journal of Pragmatics, 34, 1537-1568

Kihekaya, F. (2010). The pragmatic knowledge of Turkish EFL students in using certain request strategies. 9(1), $185-201$

Liu, S. (2004). Pragmatic strategies and power relations in disagreement: Chinese culture in higher education. New York: Universal Publishers.

Moon, K. (2001). Speech act study: differences between native and nonnative speakers' complaint strategies. The American University. [Online] Available: www.Science-direct-journal.com

Muntigl, P., \& Turnbull, W. (1998). Conversational structure and facework in arguing. Journal of Pragmatics, 29, 225-256. http://dx.doi.org/10.1016/S0378-2166(97)00048-9

Nelson, G., Al-Batal, M., \& El-Bakary, W. (2002). Directness vs. indirectness: Egyptian Arabic and US English communication style. International Journal of Intercultural Relations, 26, 39-57

Pearson, E. (1986). Agreement/disagreement: An example of results of discourse analysis applied to the oral English classroom. International Review of Applied Linguistics, 74.1, 47-61

Rees-Miller, J. (2000). Power, severity, and context in disagreement. Journal of Pragmatics, 32 (8), 1087-1111

Richard J. C., \& Schimidt.R. (1985). Dictionary of language teaching \& applied linguistics. Longman: Pearson Education.

Schmitt, N. (2002). An introduction to applied linguistics. New York: Oxford university press.

Scott, S. (2002). Linguistic feature variations within disagreements: An empirical investigation. Text, 22(2), 301-328

Takano, S. (2005). Re-examining linguistic power: strategic uses of directives by professional Japanese women in positions of authority and leadership. Journal of Pragmatics, 37, 633-666. http://dx.doi.org/10.1016/j.pragma.2004.06.007

Tannen, D. \& Kakava, Ch. (1992). Power and solidarity in modern Greek conversation: Disagreeing to disagree. Journal of Modern Greek Studies, 10, 11-34

Walko, Z. (2007). EFL research articles through the lens of pragmatic politeness. [Online] Available: http://langped.elte.hu/Walko.pdf

Watts, Richard J. (2003). Politeness. Cambridge: Cambridge University Press.

Yu, M. (2003). On universality of face: Evidence from Chinese compliment response behavior. Journal of Pragmatics, 35, 1679-1710. http://dx.doi.org/10.1016/S0378-2166(03)00074-2 
Table 1. Disagreement to the supervisor who questions the originality of the term paper she or he submits

\begin{tabular}{|c|l|l|c|}
\hline & Types of disagreement & levels & frequencies \\
\hline 1 & Irrelevancy claims & Intermediate & $15 \%$ \\
& & Upper intermediate & $5 \%$ \\
\hline 3 & Challenges & Intermediate & $20 \%$ \\
& & Upper intermediate & $10 \%$ \\
\hline 4 & Counterclaims & Intermediate & $35 \%$ \\
& & Upper intermediate & $15 \%$ \\
\hline 5 & Contradictions followed by counterclaims & Intermediate & $20 \%$ \\
& & Upper intermediate & $20 \%$ \\
\hline 6 & Message abandonment & Intermediate & $10 \%$ \\
& & Upper intermediate & $5 \%$ \\
\hline
\end{tabular}

Table 2. Disagreement to the boss

\begin{tabular}{|c|l|l|c|}
\hline & Types of disagreement & Levels & frequencies \\
\hline 1 & Irrelevancy claims & Intermediate & $10 \%$ \\
2 & Upper intermediate & \\
\hline 3 & Challenges & Intermediate & $15 \%$ \\
& & Upper intermediate & $5 \%$ \\
\hline 4 & Counterclaims & Intermediate & $10 \%$ \\
& & Upper intermediate & $15 \%$ \\
\hline 5 & Contradictions followed by counterclaims & Intermediate & $15 \%$ \\
& & Upper intermediate & $25 \%$ \\
\hline \multirow{2}{*}{6} & Message abandonment & Intermediate & $20 \%$ \\
& & Upper intermediate & \\
\hline
\end{tabular}


Table 3. Disagreement to the friend

\begin{tabular}{|c|l|l|c|}
\hline & Types of disagreement & levels & frequencies \\
\hline 1 & Irrelevancy claims & Intermediate & $15 \%$ \\
\hline 2 & Challenges & Upper intermediate & $5 \%$ \\
\hline 3 & Contradictions & Upper intermediate & $5 \%$ \\
\hline 4 & Counterclaims & Intermediate & $25 \%$ \\
& & Upper intermediate & $10 \%$ \\
\hline 5 & Contradictions followed by counterclaims & Intermediate & $25 \%$ \\
& & Upper intermediate & $20 \%$ \\
\hline 6 & Message abandonment & Intermediate & $10 \%$ \\
\hline
\end{tabular}

Table 4. Disagreement to the classmate

\begin{tabular}{|c|l|l|c|}
\hline & Types of disagreement & levels & Frequencies \\
\hline 1 & Irrelevancy claims & Intermediate & $20 \%$ \\
\hline 2 & Challenges & Upper intermediate & $5 \%$ \\
\hline 3 & Contradictions & Untermediate & $20 \%$ \\
& & Intermediate & $15 \%$ \\
\hline 4 & Counterclaims & Upper intermediate & $20 \%$ \\
\hline 5 & Contradictions followed by counterclaims & Intermediate & $20 \%$ \\
& & Untermediate & $35 \%$ \\
\hline & Message abandonment & Untermediate & $5 \%$ \\
\hline
\end{tabular}


Table 5. Disagreement to the younger sister

\begin{tabular}{|c|l|l|c|}
\hline & Types of disagreement & levels & frequencies \\
\hline 1 & Irrelevancy claims & Intermediate & $20 \%$ \\
\hline 2 & Challenges & Upper intermediate & $5 \%$ \\
\hline 3 & Contradictions & Untermediate & $15 \%$ \\
& & Upper intermediate & $10 \%$ \\
\hline 5 & Counterclaims & Intermediate & $10 \%$ \\
& & Upper intermediate & $15 \%$ \\
\hline 6 & Message abandonment & Intermediate & $30 \%$ \\
& & Upper intermediate & $50 \%$ \\
\hline
\end{tabular}

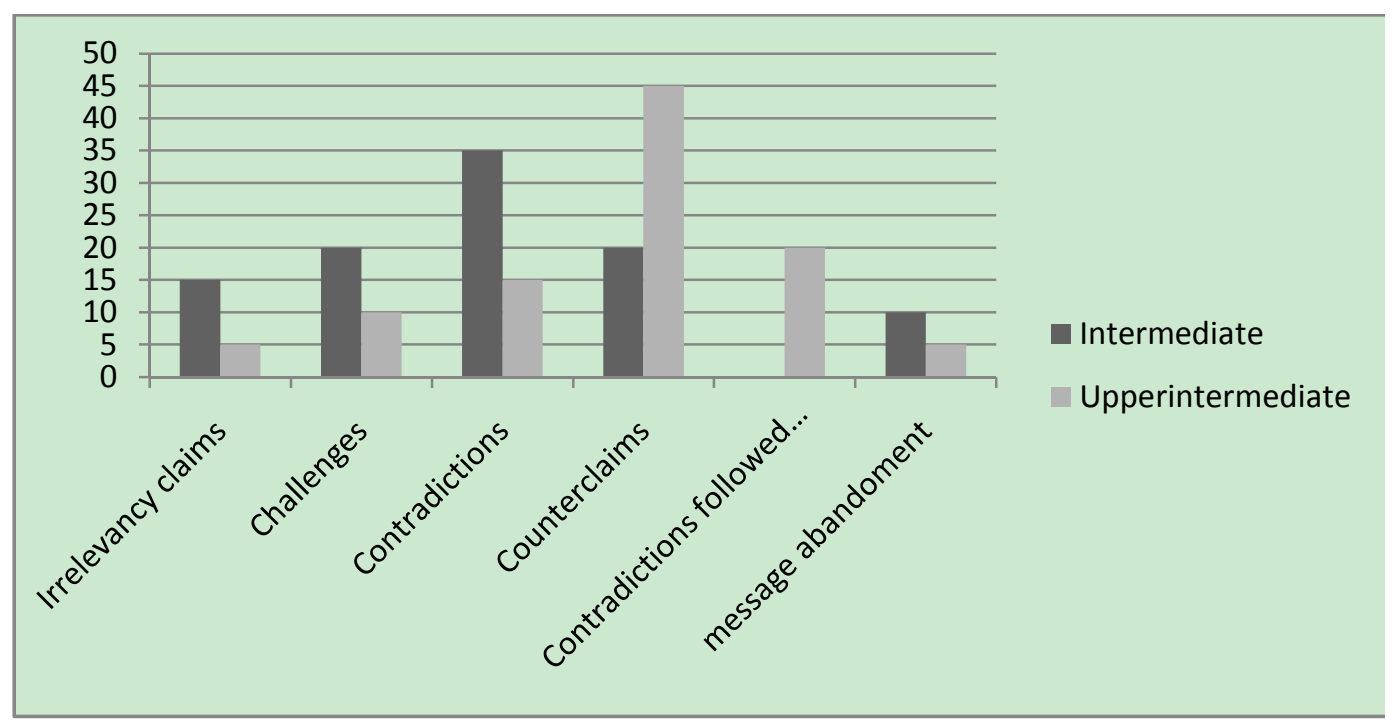

Figure 1. Disagreement to the supervisor who questions the originality of the term paper she or he submits 


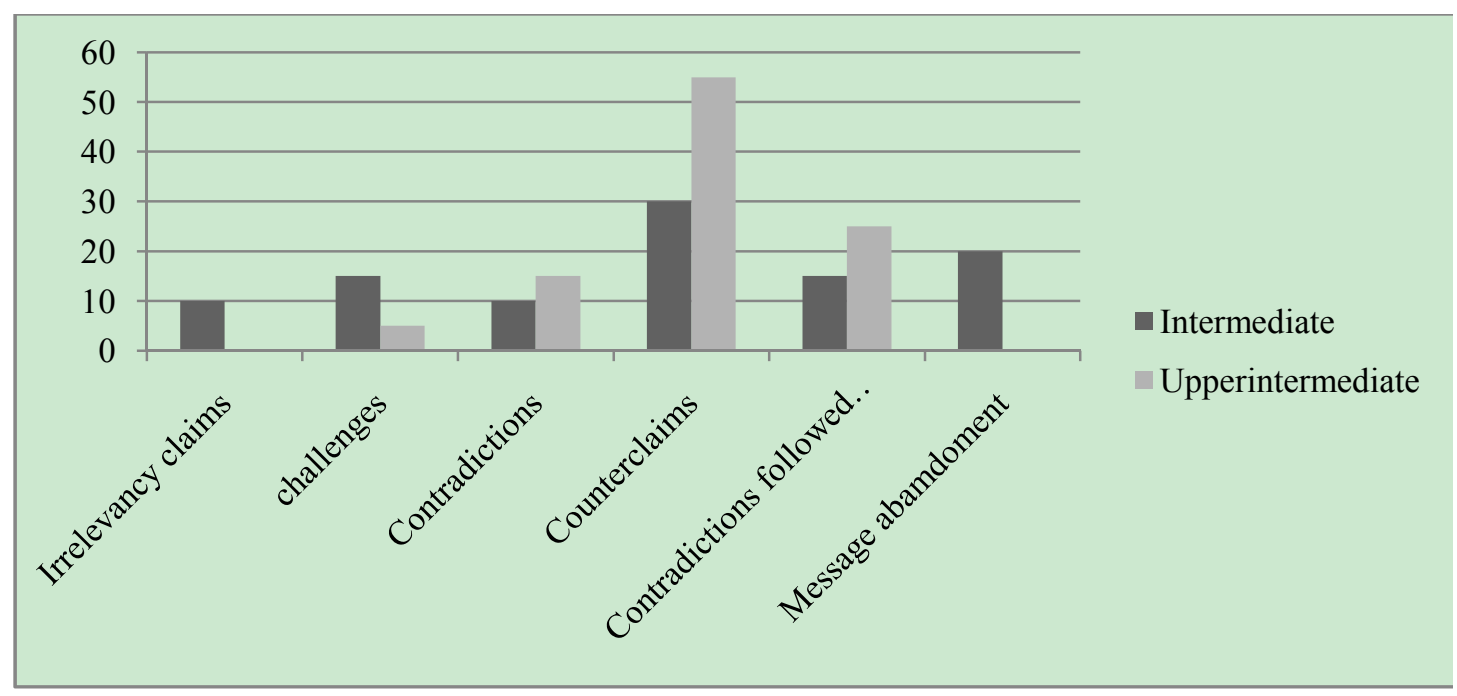

Figure 2. Disagreement to the boss

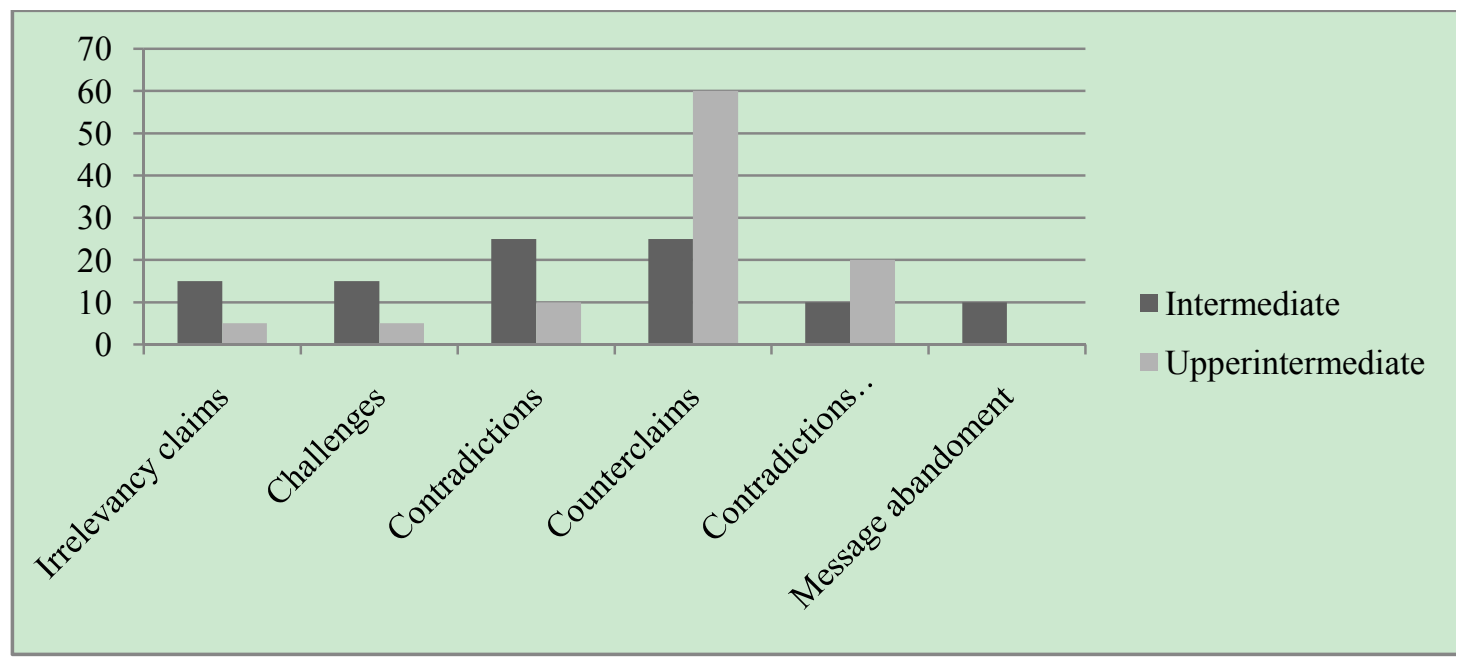

Figure 3. Disagreement to the friend 


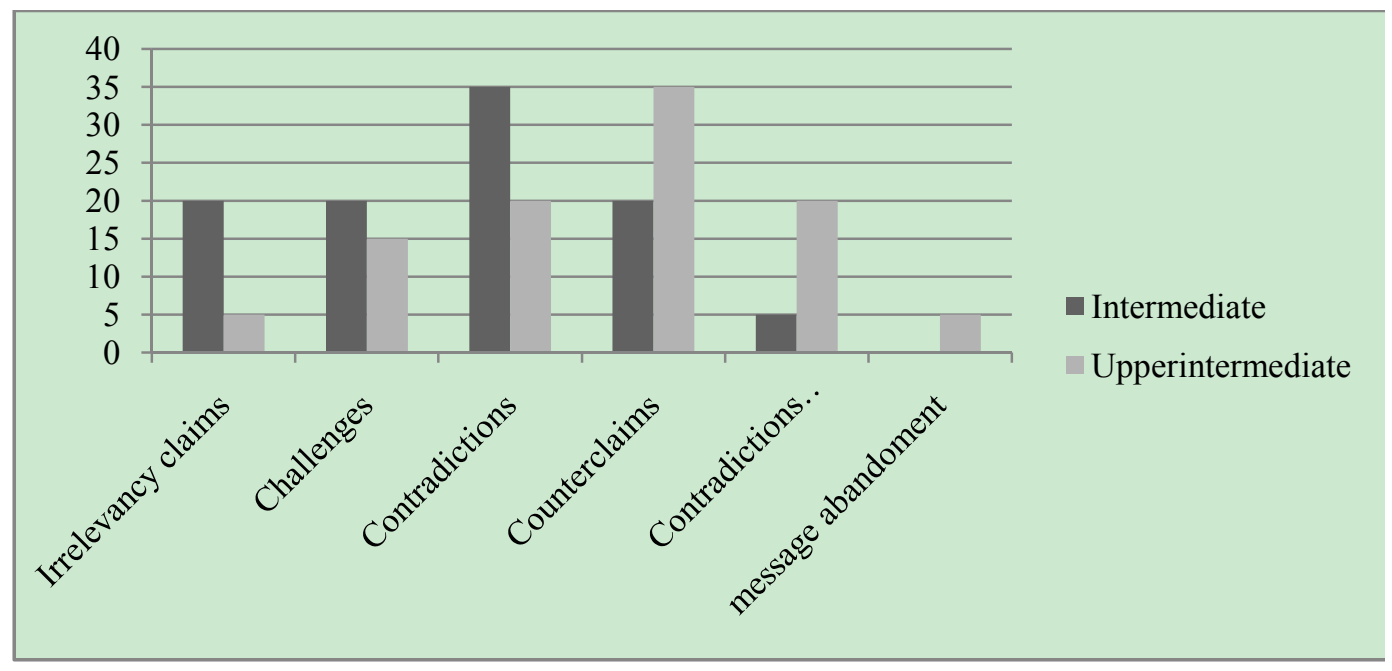

Figure 4. Disagreement to the classmate

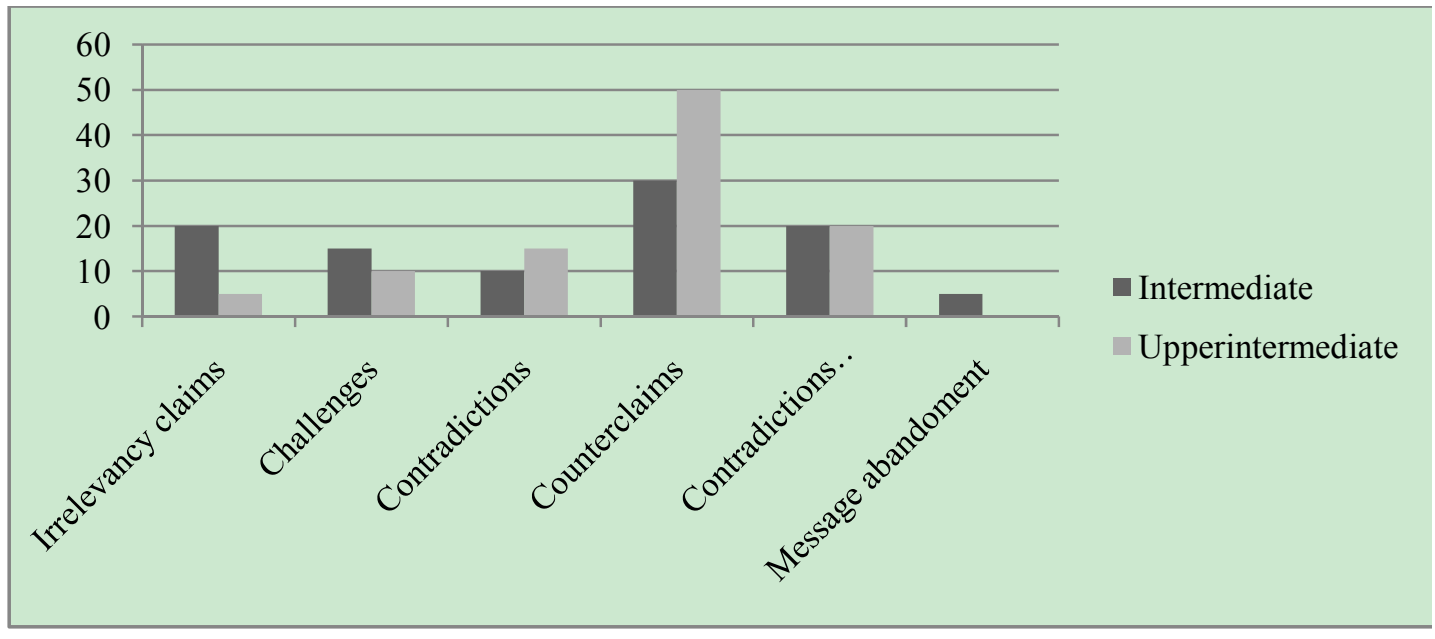

Figure 5. Disagreement to the younger sister

\section{Appendix 1}

\section{The English Version of the Discourse Completion Test}

Thank you very much for your time and help.

Your Age: _ Gender: __ Hometown:

Is English your First Language? (If yes, you don't need to answer the following questions)

For how many years have you studied English?

Have you had a chance to study English outside of the classroom?

What has your English Study focused on (i.e., grammar, translation, conversation, reading and writing skills?)

How often do you use English outside the school or university?

Five scenarios are described below in which you are expected to Disagree with the speaker on different occasions. How would you respond? Please write out what you are to SAY in real life scenarios.

1. Your supervisor questions the originality of the term paper you submit. S/he says to you, "I'm sorry, but I don't think these ideas are yours." However, they are yours. In response, you will say, 
$"$

2. You work in a company. Your boss presents you with a plan for reorganization of the department that you are certain will not work. Your boss says isn't it a great plan? In response, you will say,

$"$

3. Your friend makes the following comment on your thesis, "I think you should supply more data to support your arguments. You know, your conclusion is a little bit weak." However, you think that there has been enough evidence and the problem is how to give a better explanation of the data. In response, you will say,

$"$

4. In a seminar class on the effect of modern technology, one of your classmates says, "The so-called modern technology is endangering the environment. It causes too much pollution". However, you believe such problems are only temporary and can be solved gradually. In response, you will say:

$"$

5. You are watching the movie Titanic with your younger sister at home. When the ship is about to sink and the first mate calls out, "Women and children first" to get on the lifeboat, your sister suddenly blurts out, "It's really unfair and prejudiced to women: we're no weaker than men. Why should women instead of men go first with the children?" In your opinion, women are, physically speaking, not as strong as men. Your response will be:

$"$ 